\title{
Profiling of smokers and snuffers among young Finnish men - cross-sectional epidemiological study
}

Jari Päkkilä1, Vuokko Anttonen², Pertti Patinen ${ }^{3}$, Kai Nyman ${ }^{4}$, Kirsi Valkeapää4, Dowen Birkhed $^{5}$, Leo Tjäderhane ${ }^{2,6}$, Tarja Tanner ${ }^{2}$

${ }^{1}$ Department of Mathematical Sciences, University of Oulu, Finland, ${ }^{2}$ Institute of Dentistry, University of Oulu; Medical Research Center, Oulu University Hospital and University of Oulu, ${ }^{3}$ Centre for Military Medicine, Finnish Defence Forces, Riihimäki, Finland, ${ }^{4}$ Finnish Defence Research Agency, Human Performance Division, Järvenpää, Finland, ${ }^{5}$ University of Gothenburg, Gothenburg, Sweden, ${ }^{6}$ Department of Oral and Maxillofacial Diseases, University of Helsinki, Helsinki University Hospital, Helsinki, Finland

\section{Corresponding author:}

Tarja Tanner

tarja.tanner@fimnet.fi

Institute of Dentistry

P.O. Box 5281

FI-90014 University of Oulu, Finland

+358404178501

Fax: +35885375560 


\section{Abstract \\ Objective}

The purpose of this study was to get new information from several sources about the background factors of Finnish smokers, snuffers, and dual users. Profiles of young smokers and snuffers were investigated in association with restorative treatment need, oral hygiene, eating habits, physical activity, BMI, psychological, and socioeconomic factors.

\section{Material and Methods}

The study group comprised 3,420 conscripts. The data was collected from four different sources: a health examination including an oral health screening, a computer-based questionnaire for investigating individual background factors, a psychological test assessing cognitive skills, and the Cooper test. Statistical analyses comprised cross tabulation and binary logistic regression modeling.

\section{Results}

The odds for smoking were the greatest among those who had DT (Decayed teeth) $>0$, used energy drinks or alcohol regularly, or whose parents were divorced. A score of $\geq 2,900$ meters in the Cooper test, a higher physical exercise level, a higher own education level, and using sports drinks decreased the odds for smoking.

The odds for snuffing were higher among those who ran $>2,500$ meters in the Cooper test, had a $\mathrm{BMI}$ of $\geq 25$, used sports/energy drinks, or exercised regularly, and lower among those who achieved good results in the cognitive test. Using energy/sports drinks or alcohol were positively and a higher education level was negatively associated with dual use.

\section{Conclusions}

Along with increasing prevalence of snuffing, heterogeneity is likely among snuffers. Good cognitive skills may prevent from smoking and snuffing.

\section{Keywords}

epidemiology, health behavior, profiling, smoking, snuffing 


\section{Funding}

This work was supported by The Finnish Dental Society Apollonia by grants to T.T. The funder had no role in the study design, data collection and analysis, decision to publish, or preparation of the manuscript.

\section{Declaration of Interests}

There are no conflicts of interest to disclose.

\section{Introduction}

Health behaviors of Finnish young males may be harmful to oral as well as general health [1, 2]. According to our previous study, in the population representing young men born in the early 1990s, almost $40 \%$ of Finnish young males are daily smokers, and almost $20 \%$ use snuff at least occasionally during the week [1]. These proportions are even higher than in previous studies from Finland $[3,4,5]$.

In 2016 among 16-24-year-old Swedish men, the prevalence of daily smoking (only) and snuffing (only) was $8.5 \%$ and $15 \%$, respectively [6]. The corresponding figures among 16-24-year-old Norwegian men were $5 \%$ and $21 \%$ [7]. In Norway, the increasing snuff use has been called an "epidemic-like phenomenon" among the young (16-24-year-olds) [8]. The prevalence of snuff users has also increased during the past decade among 18-44-year-olds in the United States [9]. There are approximately 2.89 million active users of snuff, which amounts to $2.8 \%$ of the $18-44$-year-olds in the U.S. [9]. Among young Swiss men, the most common smokeless tobacco product is nasal dry snuff $(8 \%)$, and the proportion of snuff users is $3 \%[10]$.

In Finland and other Nordic countries, the moist snuff called "snus" is the most common smokeless tobacco product. It is used on oral mucosa, usually in the sulcus under the upper lip.

Long-term effects of smoking, including on oral health, have been extensively studied [11, 12, 13]. However, there are no studies on the effects of snuff use, especially when the use has started already at a young age. The harmful effects of snuff use depend on the length of the period the 
product has been used, as well as on the amount of snuff used [8]. In addition, dual use, or use of snuff with other tobacco products, is relatively common not only in Finland [3] but also in Norway [7] and Sweden [6], which may interfere with the outcome in studies on health effects of snuff use.

Socio-demographic and background factors of snuffers have been systematically described in Sweden [14] but not in Finland. Snuffing has been reported to be common among physically active people $[5,15]$. On the other hand, some studies have reported that physical activity is a protective factor against smoking [16, 17], but there are also opposite findings [18]. According to studies from Norway [19], Sweden [20], and Finland [21], smoking and snuffing are both associated with the use of other intoxicants. Pedersen et al. [19] found that both snus users and smokers reported more adverse socioeconomic backgrounds and less favorable school adjustment compared to non-users. Findings among Swedish adolescents were in the same line: a lower parental education, poorer family mood, poorer self-rated health, and poorer self-esteem were all possible predictors of smoking [20].

The aim of this study was to profile young smokers and snuffers. This was investigated in association with restorative treatment need, oral hygiene, eating habits, physical activity, BMI, and psychological and socioeconomic factors.

\section{Material and Methods}

The study is part of the project "Oral health of the conscripts 2011". The original cross-sectional study was designed in the spring of 2010 , and was carried out at 20 garrison health centers (a total of 24) of the Finnish Defence Forces in January and July 2011. The protocol, criteria, calibration, and data have been described in detail in earlier articles on the project [22, 23, 24].

The study group comprised 3,420 conscripts born in 1990, 1991, or 1992 (the mean age was 19.6 years). The data of this study was collected from four different sources (Figure 1) on Finnish conscripts while they were performing their military service in 2011 . This study only comprised data of those conscripts for whom all the information from the four different sources explained below was available. The conscripts' caries status and general health information were derived from their basic data, which were available for 13,564 men. In connection with the oral screening, the conscripts had 
an opportunity to answer a computer-based questionnaire on their individual background factors and health behaviors, i.e. dietary and oral hygiene habits [22]. Answering the questionnaire was voluntary, but no one refused. Because of the time limit, only 8,539 ultimately answered the questionnaire. In this study, two additional data sources of the Finnish Defence Forces were used: a psychological test assessing cognitive skills (Finnish Defence Forces' Basic Ability Test; $n=10,112$ ) and a 12-minute running test (the Cooper test; $n=9,830$ ), which both are obligatory to every conscript during the first two weeks in military service. Because the proportion of the female conscripts was very small among the study group, their data were excluded from the study population.

\section{Finnish Defence Forces' Basic Ability Test}

The ability test scores used in this study were developed in the Finnish Defence Forces. This obligatory test battery was designed to measure general ability and logical thinking. The results of the tests were used to select conscripts to leadership training during their military service. The test battery is described in detail elsewhere $[25,26]$. In brief, the test has three parts: verbal, arithmetic, and visuospatial reasoning. Each part consists of 40 multiple-choice questions whose degree of difficulty ranges from very easy to very complicated. In the verbal reasoning test, the questions concern synonyms, antonyms, assessing if words belong to the same category as a provided word, and relationships between two word pairs. The arithmetic reasoning test comprises assignments of number series and verbally expressed short problems, simple arithmetic operations, and specifying relationships between two pairs of numbers. The visuospatial reasoning test is analogous to the widely used Raven's Progressive Matrices [27], in which the subject has to decide which figure completes the matrix.

The maximum score for each part is 40 , and the scores are converted into stanines (standard nines). In this study, we used the total score of the Finnish Defence Forces' Basic Ability Test, which means that the stanine scores of the verbal, arithmetic, and visuospatial tests are summed together and the distribution of the sum scores is converted into stanines again (range 1-9). 


\section{2-minute running test (the Cooper test)}

The Cooper test is a traditional method to predict the maximum oxygen uptake, VO2Max, in populations. In the Cooper test, each conscript runs as far as possible within 12 minutes. The result is reported with the precision of 5 meters. [28]

\section{BMI (Body Mass Index)}

The BMI values were sourced from the original data of the Finnish Defence Forces; the conscripts' height and weight are measured in the health examination. In the analyses, BMI was calculated as the weight in kilograms divided by the square of the height in meters.

\section{$D T, D M F T$}

The screening of the oral health of the conscripts was carried out as part of the obligatory general health inspection. Restorative treatment need and history (DT=decayed teeth, DMFT=decayed, missing, and filled teeth) were used as confounding variables for the analyses [29].

\section{Questionnaire}

The responses to the following questions were used: Do you smoke? (not at all / 1-5 cigarettes daily / 10-20 cigarettes daily / >20 cigarettes daily); Do you use snuff? (never or hardly ever / every day or almost every day / occasionally); Do you consume alcohol? (No / Less than once a month / About once a month / About every other week / About every week / More than once a week); What is your education? (comprehensive school / vocational school / university of applied sciences / vocational school and matriculation exam or upper secondary school / matriculation exam or upper secondary school / college or university / or other); What is your mother's education? (comprehensive school / vocational school / university of applied sciences / college or university / or other); Do your parents live together? (Yes / No); How often do you drink the following snacks: sport drinks / energy drinks? (never or hardly ever / every day or almost every day / occasionally during the week); and How often do you brush your teeth? (never or hardly ever / occasionally / every day). For those persons who reported brushing their teeth every day, a new question opened: How many times a day do you 
brush your teeth? (once a day / twice a day / more than two times a day). Over past six months how often have you exercised or done sport? (never or hardly ever / every day or almost every day / occasionally during the week)

\section{Factors associated with the place of residence}

The conscripts' mother language was also used as a confounding variable in the analyses (Finnish, Swedish, or other). In this study, information about the mother tongue given by the conscript himself was used instead of the official main language in the home municipality.

\section{Statistical issues}

A new variable was created to allow analyzing persons according to their smoking and snuffing habits (smoking / no snuffing, no smoking / snuffing, smoking / snuffing, no smoking / no snuffing) (Figure 2).

Smoking and snuffing were used as response variables in the analyses. The responses to the questions on smoking and using snuff were dichotomized as follows: those not smoking at all and the rest and those using snuff never or hardly ever and the rest

The confounding variables were dichotomized as follows: those who have at least one decayed tooth $(\mathrm{DT}>0)$ and the rest; those drinking sport drinks at least occasionally during the week and the rest; those drinking energy drinks at least occasionally during the week and the rest; those consuming alcohol at least once a week and the rest. The two questions dealing with tooth brushing were combined and categorized into three groups as follows: those brushing teeth two times or more daily, those brushing teeth daily, and the rest. The education level of the conscripts was categorized into three groups: vocational school, matriculation exam or upper secondary school, and the rest. The education level of the conscripts' mothers was dichotomized into two groups: comprehensive school and vocational school and the rest.

For statistical analyses, the following confounding variables were categorized as follows: DMFT values 0, 1-4 and >4; BMI values $<25,25-30$ and $>30$; results of the Cooper test $<2,500,2,500-$ 2,899, >2,900; results of the Basic Ability Test 1-2, 3-7, and 8-9. 
Cross tabulation was used to analyze the association between smoking and snuffing and again between smoking/using snuff and the Basic Ability Test and Cooper test scores. The significance between the groups was tested by chi-squared tests. Statistical significance was determined at $p<0.05$. For analyzing, the factors associated with smoking, snuffing, and dual use (bivariate responses smoking and the rest, snuffing and the rest, and dual use and the rest), binary logistic regression analyses were conducted. The results' OR values and 95\% confidence intervals from the regression analyses were shown by graphs. All the analyses were executed and figures drawn using the SPSS software (versions 23.0, SPSS, Inc. 2015, Chicago, IL) and R software (version 3.2.3 Patched. A language and environment for statistical computing; R Foundation for Statistical Computing, Vienna, Austria, URL; http://www.R-project.org).

\section{Ethical issues}

The data were collected from the archives of the Finnish Defence Forces with their permission. For identification, ID numbers were created for all the conscripts. The key for the IDs and the patient records are kept in the archives of the Defence Forces. The conscripts gave their consent to use their patient records by answering the voluntary computer-assisted questionnaire. With respect to the ethics, the main research plan was evaluated by the Ethical Committee of the Northern Ostrobothnia Hospital District, and positive consent was given on March 30, 2010. The Centre for Military Medicine of the Finnish Defence Forces gave its permission for the study in June 2010 (AG14218/23.6.2010).

\section{Results}

The prevalence of only smoking, only snuffing, and dual use were $25.8 \%(n=882), 9.7 \%(n=333)$ and $10.1 \%(n=347)$, respectively (Table 1$)$.

The mean Cooper test score among the study population was 2,500 meters (SD 349.0), and 2,540 meters among the non-users (SD 348.7) (Figure 2). Among those who used only snuff, the mean value was 2,615 meters (SD 348.7), i.e. 240 meters more than of those only smoking 
(2,375 meters; SD 335.2). The Cooper test score of the dual users was a little less than the mean score (2,470 meters; SD 343.0) of the entire study group. (Figure 2)

Figure 2 also shows the distribution of the ability scores in association with smoking and snuffing. The highest mean value 5.5 (SD 1.9) was found among the non-users and the lowest 4.6 (SD 1.7) among the smokers. The mean ability score of those who used only snuff was 4.85 (SD 1.6) and of the dual users 4.7 (SD 1.7), which are below the mean of the entire study population 5.1 (SD 1.8). All the differences between the groups were statistically significant $(p<0.001)$. (Figure 2$)$. Ability scores 1 to 4 were more common among the only smoking and the dual use groups compared to the other groups. Ability score 5 was most common among the only snuff users, and the rest of the scores (6 to 9 ) were most common among conscripts who did not use any tobacco products.

The results from the binary logistic regression analyses showed differences of odds ratios (OR, 95\% $\mathrm{Cl}$ ) between snuff users, smokers, and dual users in association with different independent and confounding variables (Figure 3). The odds for the use of snuff were significantly higher among those who ran in the Cooper test more than 2,500 meters $(1.43,[1.06,1.91])$, and association was stronger when the result of the Cooper test exceeded 2,900 meters (2.66, [1.86, 3.79]). The same was true with the BMI values and using sports drinks. BMI 25-30 (1.33, [1.01, 1.76]) and occasional use of sports drinks $(2.10,[1.61,2.73])$ were associated with snuff use, but the association became stronger with higher BMI values $(1.94,[1.23,3.05])$ and more frequent consumption of sports drinks $(2.92$, [1.80, 4.75]). In addition, a higher exercise level (2.92, [1.27, 6.72]) and using energy drinks regularly $(1.51,[1.17,1.94])$ were significantly associated with snuff use. Ability scores 8-9 (OR 95\% Cl 0.40, $[0.20,0.79])$ were positively associated with snuff use. (Figure 3).

The odds for smoking were greater among those who had restorative treatment need (DT>0) (1.31, $[1.08,1.60])$ or used energy drinks occasionally $(1.73$, $[1.34,2.24])$, but particularly among those who used energy drinks daily $(2.91,[1.95,4.35])$. Smoking was also associated with weekly alcohol use $(1.72,[1.43,2.07])$ and the relationship of the conscript's parents $(1.36,[1.14,1.63])$ (Figure 3). The score of 2,900 meters or more in the Cooper test $(0.43,[0.30,0.60])$, a higher exercise level (0.59, [0.44, 0.78]), a higher own education level $(0.37,[0.30,0.45])$, and using sports drinks 
occasionally $(0.62,[0.49,0.78])$, and especially daily $(0.46,[0.27,0.78])$, were all negatively associated with smoking (Figure 3).

The odds for dual use (smoking and snuffing) were similar to the odds for smoking (Figure 3). Using energy drinks occasionally $(1.73,[1.34,2.24])$ or daily $(2.91$, [1.95, 4.35]), weekly use of sports drinks $(1.69,[1.29,2.22])$ or alcohol $(2.10,[1.65,2.67])$, as well as other education level $(1.48,[1.08,2.03])$ than vocational school or matriculation exam or upper secondary school were all associated with dual use. The conscript's higher education level $(0.66,[0.49,0.88])$ was positively associated with dual use. (Figure 3).

\section{Discussion}

According to this cross-sectional population-based study among healthy Finnish men, smoking and snuffing are surprisingly common. More than one third reported smoking daily, and almost one fifth using snuff at least occasionally during the week. The reasons for this phenomenon have been speculated in our previous studies on this data [1, 2].

It should be remembered that the Finnish Defence Forces' Basic Ability Test measures cognitive skills, and the educational background may affect that. To our knowledge, it is unique to have results of psychological tests available for statistical analyses in a large-scale study like the present one. An interesting finding in this study is that the higher ability scores were found among the non-users. The reasons for that can only be speculated. Perhaps the decision to smoke or use snuff is mostly based on knowledge, even if the influence of friends [30] and family [31] on health habits of adolescents is well known.

A high physical exercise level and a good result in the Cooper test are significantly associated with snuff use in this study. According to some studies, snuffing is more common among physically active people [5, 15] and snuff use is popular in sports [32], particularly in team sports such as ice hockey $[5,15]$. This is in line with our findings. Such findings may explain our result that regular use of energy or sports drinks is associated with snuff use. In this study, weekly alcohol use was associated with 
smoking and dual use, but not with snuffing. That is partly in concordance with many previous studies which have found that snuffing may be associated with alcohol use and smoking [14, 19, 21]. An interesting finding of this study is that being overweight is highlighted in the snuffing group. This finding is contradictory to findings from Sweden [14]. Engström et al. [14] have reported that being underweight is associated with snus use and being overweight with smoking among the Swedish adult population. Light overweight may be explained by big muscles, which are common among athletes in some sports, such as ice hockey. The higher proportion of overweight persons may also tell that snuff use is no longer a habit of a marginal group.

According to our previous study on the same population, we found that smoking was associated with other unhealthy habits [1,2] which may lead restorative treatment need [1] and poor physical condition, which was also confirmed in this study. It is interesting that the socioeconomic background is associated with smoking, snuffing, and dual use in every analysis no matter what other explanatory variables are included in the analyses $[9,14,19,20]$.

When we compared snuffers, smokers, and dual users, it could be seen that associations with explanatory factors are often the opposite for smoking and snuffing. Only the association with the ability scores are similar for both snuffing and smoking. Among dual users, the explanatory factors mainly affect in the same way as among smokers.

It could franklybe said that Finnish young men who smoke may do not do much physical exercise, have restorative treatment need, consume energy drinks or alcohol, have a lower educational level, and have divorced parents. On the other hand, a typical snuffer may do physical exercise regularly, run more than 2500 meters in the Cooper test, have a BMI over 25 , consume energy or sport drinks regularly, brush teeth at least twice a day, and have ability score 7 or lower. A typical dual user may has a lower educational level and consumes alcohol or energy or sport drinks regularly.

If we compare the results of this study to an extensive study from Sweden [14], there are not many differences between Finnish smokers and snuffers and their Swedish counterparts. The profiles of snuffers positioned between the profiles of smokers and non-users both in the study by Engström et al. [14] and in this study. Otherwise, in the present study, it is much clearer that snuff use is common among physically active persons. 
A great advantage of our study is that we had access to large-scale data from several sources: the clinical examination, questionnaire, psychological tests, and the Cooper test. All these examinations are obligatory to every conscript during their first weeks of military service. The drop-out rate was thus zero. Because of time constraints, only about $60 \%$ of the conscripts answered the questionnaire.

A shortcoming of this study is the lack of information about the history of smoking and snuff use. The information about smoking and snuffing was received through the questionnaire instead of, for example, from blood tests. It can be speculated that the prevalence could be even higher because people sometimes tend to answer more positively than negatively. There are also some weaknesses in the study design. On the basis of this cross-sectional study, it is not possible to identify possible causal factors behind smoking and snuff use. Longitudinal studies on the topic would be interesting. It would also be valuable if data of the sources used in this study were available for the entire conscript population, i.e. the total of 13,564 young men. In addition, the female conscripts were not included in the present study, which could be regarded as a shortcoming of this study.

\section{Conclusions}

The results show that snuffing is no longer practiced by a marginal group, and there are different kinds of snuffers in this study population. It can be speculated that if the prevalence of snuff use still continues to increase after this decade, even more heterogeneity will be seen among the users. Good cognitive skills may prevent from smoking and snuffing, which hopefully helps to promote continuous preventive work among adolescents at schools.

\section{Acknowledgments}

The study was conceived and designed by T.T, J.P, P.P, and V.A. The data were analyzed by J.P. The paper was written by J.P, V.A, P.P, K.N, K.V, D.B, L.T, and T.T. The abstract of this study was presented at the IADR conferences in San Francisco on March 22-25, 2017. 


\section{References}

1. Tanner $T$, Kämppi A, Päkkilä $J$ et al. Association of smoking and snuffing with dental caries occurrence in a young male population in Finland: A cross-sectional study. Acta Odontol Scand. 2014;72:1017-1024.

2. Tanner T.Healthy young adults' oral health and associated factors. Academic Dissertation, University of Oulu, Finland. 2015 Available from; $\quad$ http://urn.fi/urn:isbn:9789526208558.

3. Kinnunen JM, Pere L, Lindfors P, et al. The Adolescent Health and Lifestyle Survey 2015. Adolescent smoking, alcohol and substance use in 1977-2015. Sosiaali- ja terveysministeriön raportteja ja muistiota 2015:31, pp. 21-28, Helsinki (In Finnish with an English summary). Available from: $\quad$ https://www.julkari.fi/bitstream/handle/10024/126379/URN_ISBN_978-952-00-35921.pdf?sequence $=1$

4. Helldán A, Helakorpi S, Virtanen S, et al. Health Behaviour and Health among the Finnish Adult Population, Spring 2012. National Institute for Health and Welfare (THL), Report 2013:15, pp. 1213, 711. Helsinki, 2013. Available from: https://www.julkari.fi/bitstream/handle/10024/110537/URN_ISBN_978-952-245-9312.pdf?sequence $=1$

5. Mattila VM, Raisamo S, Pihlajamäki $\mathrm{H}$, et al. Sports activity and the use of cigarettes and snus among young males in Finland in 1999-2010. BMC Public Health. 2012;12:230. doi: 10.1186/14712458-12-230.

6. Statistiska centralbyrån. Tobacco habits by indicator, age and sex. Percentage and estimated numbers in thousands. Year 2008-2009 - 2016-2016- Latest update 4/2017. Available from; http://www.statistikdatabasen.scb.se/pxweb/en/ssd/START_LE_LE0101_LE0101H/LE0101H25 /?rxid=4c116499-0bf1-4215-947b-5d046c0a9e10 
7. Statisstisk sentralbyrå, Statistics Norway. Smoking habits 2016. Latest update 1/2017. Available from:

https://www.ssb.no/statistikkbanken/selecttable/hovedtabellHjem.asp?KortNavnWeb=royk\&CMSS ubjectArea=helse $\&$ PLanguage $=1 \&$ checked $=$ true

8. Bhattacharuua N. Trends in the use of smokeless tobacco in United States, 2000-2010. Laryngoscope. 2012;122:2175-2178.

9. Fischer R, Clair C, Studer J, et al. Prevalence and factors associated with use of smokeless tobacco in young Swiss men. Eur J Public Health. 2014;24:459-64.

10. Bernabé E, Delgado-Angulo EK, Vehkalahti MM, et al Daily smoking and 4-years caries increment in Finnish adults. Community Dent Oral Epidemiol. 2014;42:428-434.

11. Lim SS, Vos T, Flaxman AD et al. A comparative risk assessment of burden of disease and injury attributable to 67 risk factors and risk factor clusters in 21 regions, 1990-2010: a systematic analysis for the Global Burden of Disease Study 2010. Lancet 2012. 380:2224-2260.

12. Samet JM, Norman LA, Wilbanks C editors. The Health Consequences of Smoking: A Report of the Surgeon General. Atlanta, GA: U.S. Department of Health and Human Services, Centers for Disease Control and Prevention, National Center for Chronic Disease Prevention and Health Promotion, Office on Smoking and Health, 2004. Available from: http://www.cdc.gov/tobacco/ data_statistics/sgr/2004/

13. Norwegian Institute of Public Health. Health risks of Scandinavian snus consumption 2014, Oslo, Norway. In Norwegian with an English summary. Available from: https://www.fhi.no/globalassets/migrering/dokumenter/pdf/helserisiko-ved-bruk-av-snus-pdf.pdf 14. Engström K, Magnusson C, Galanti MR. Socio-demographic, lifestyle and health characteristics among snus users and dual tobacco users in Stockholm County, Sweden. BMC Public Health. 2010;10:619. doi: 10.1186/1471-2458-10-619.

15. Rolandsson M, Hallberg LR, Hugoson A. Influence of the ice-hockey environment on taking up snuff: an interview study among young males. Acta Odontol Scand. 2006;64:47-54.

16. Audrain-McGovern J, Rodriguez D, Wileyto EP, et al. Effect of team sport participation on genetic predisposition to adolescent smoking progression. Arch Gen Psychiatry. 2006;63:433-441. 
17. Bergamaschi A, Morri M, Resi D, et al. Tobacco consumption and sports participation: a survey among university students in northern Italy. Ann Ig. 2002;14:435-442.

18. Verkoojien KN, Kremers GA, Kremers SP. The association between leisure time physical activity and smoking in adolescence: An examination of potential mediating and moderating factors. Int $\mathrm{J}$ Behav Med. 2008;15:157-163.

19. Pedersen W, von Soest T. Tobacco use among Norwegian adolescents: from cigarettes to snus. Addiction. 2014;109:1154-1162.

20. Joffer J, Burell G, Bergström E, et al. Predictors of smoking among Swedish adolescents. BMC Public Health. 2014;14:1296. doi: 10.1186/1471-2458-14-1296

21. Tseveenjav B, Pesonen P, Virtanen Jl. Use of snus, its association with smoking and alcohol consumption, and related attitudes among adolescents: the Finnish National School Health Promotion Study. Tob Induc Dis. 2015 Oct 24;13:34.

22. Anttonen V, Tanner T, Kämppi A, et al. A methodological pilot study on oral health of Finnish young males. Dent Hypotheses. 2012;3:106-111.

23. Kämppi A, Tanner T, Päkkilä J, et al. The geographical distribution of dental caries prevalence and associated factors in young adults in Finland. Caries Res. 2013;47:346-354.

24. Tanner T, Kämppi A, Päkkilä J, et al. Prevalence and polarization of dental caries among young, healthy adults - cross-sectional epidemiological study. Acta Odont Scand. 2013;71:1436-442.

25. Tiihonen J, Haukka J, Henriksson M, et al. Premorbid intellectual functioning in bipolar disorder and schizophrenia: results from a cohort study of male conscripts. Am J Psychiatry. 2005;162:19041910.

26. Tuovinen S, Raikkonen K, Kajantie E, et al. Hypertensive disorders in pregnancy and intellectual abilities in the offspring in young adulthood: The Helsinki Birth Cohort Study. Ann Med. 2012;44:394403.

27. Raven J. The Raven's Progressive Matrices: change and stability over culture and time. Cognit Psychol. 2000;41:1-48.

28. Pihlainen K, Santtila M, Ohrankämmen O, et al. Puolustusvoimien kuntotestaajan käsikirja. Finnish Defence Forces, Helsinki, Finland. Edita Prima Oy, 2nd Edition 2011 p. 32 (In Finnish) 
Available from: http://puolustusvoimat.fi/documents/1948673/2258811/PEVIESTOSkuntotestaajank\%C3\%A4sikirja-2015/332148cf-be2e-49ea-8fa2-0df6423724fc

29. Tanner T, Päkkilä J, Karjalainen K, et al. Smoking, alcohol use, socio-economic background and oral health among young Finnish adults. Community Dent Oral Epidemiol. 2015;43:406-414.

30. Heikkinen AM, Broms U, Pitkäniemi J, et al. Key factors in smoking cessation intervention among 15-16-year-olds. Behav Med. 2009;35:93-99.

31. Busch V, De Leeuw JR, Zuithoff NP, et al. A Controlled Health Promoting School Study in the Netherlands: Effects After 1 and 2 Years of Intervention. Health Promot Pract. 2015;16:592-600.

32. Henninger S, Fischer R, Cornuz J, et al. Physical Activity and Snus: Is There a Link? Int. J. Environ. Res. Public Health. 2015:12;7185-7198. 


\section{Figure legends}

Figure 1. Description of the study population.

Figure 2. Distribution of the results from the Cooper test and the Finnish Defence Forces' Basic Ability Test among the study population, categorized into four groups based on the smoking and snuff using habits.

Figure 3. Odds ratios and $95 \%$ confidence intervals $(95 \% \mathrm{Cl})$ from a binary logistic model for using snuff, smoking, and dual use according to the different explanatory factors. 
Table 1. Distribution of using snuff in different categories of smoking.

Do you use snuff?

Total (n)

$\begin{array}{lll}\text { Never or hardly } & \text { Occasionally } & \begin{array}{l}\text { Every day or } \\ \text { ever (\%) }\end{array} \\ & \text { (\%) } & \text { day (\%) } \\ & & \text { davery }\end{array}$

\begin{tabular}{|c|c|c|c|c|c|}
\hline \multirow{4}{*}{$\begin{array}{l}\text { Do you } \\
\text { smoke? } \\
(\%)\end{array}$} & $\begin{array}{l}\text { No } \\
(64.1 \%)\end{array}$ & 84.8 & 5.8 & 9.4 & $\begin{array}{l}100.0 \\
(2,191)\end{array}$ \\
\hline & $\begin{array}{l}1 \text { to } 5 \\
\text { (13.7\%) }\end{array}$ & 65.9 & 19.1 & 15.0 & $\begin{array}{l}100.0 \\
(467)\end{array}$ \\
\hline & $\begin{array}{l}10 \text { to } 20 \\
(20.8 \%)\end{array}$ & 76.3 & 17.5 & 6.2 & $\begin{array}{l}100.0 \\
(710)\end{array}$ \\
\hline & $\begin{array}{l}\text { more than } \\
20(1.5 \%)\end{array}$ & 61.5 & 23.1 & 15.4 & $\begin{array}{l}1.5 \\
(52)\end{array}$ \\
\hline Total (n) & & $\begin{array}{l}2,740 \\
80.1 \%\end{array}$ & $\begin{array}{l}352 \\
10.3 \%\end{array}$ & $\begin{array}{l}328 \\
9.6 \%\end{array}$ & $\begin{array}{l}3,420 \\
100.0 \%\end{array}$ \\
\hline
\end{tabular}

